\title{
Successful percutaneous mechanical thrombectomy of an Impella CP-related femoral artery thrombosis
}

\author{
Sophie Degrauwe ${ }^{1}$, Juan F. Iglesias ${ }^{1}$, Frédéric Glauser ${ }^{2}$, Marco Roffi ${ }^{1}$ \\ ${ }^{1}$ Division of Cardiology, Geneva University Hospitals, Geneva, Switzerland \\ ${ }^{2}$ Division of Angiology, Geneva University Hospitals, Geneva, Switzerland
}

A 77-year-old female was admitted for non-ST-segment elevation myocardial infarction. Electrocardiogram demonstrated $2 \mathrm{~mm}$ ST depression from V2-V6. High sensitivity troponins were elevated (53 $\rightarrow 120 \mathrm{ng} / \mathrm{L}$ [treshold for positivity: $14 \mathrm{ng} / \mathrm{L}])$. Coronary angiogram showed bitroncular coronary artery disease with a severe lesion of the proximal to distal left anterior descending (LAD) coronary artery, treated by angioplasty with 4 drug eluting stents. Percutaneous revascularization was complicated by no reflow in the LAD leading to cardiogenic shock. Impella CP was inserted for hemodynamic support using a left femoral artery approach and a 14 French sheath. Following stabilization of patient's hemodynamics, retrieval of the Impella CP was performed subsequently on day 3 . Hemostasis of the left common femoral artery was obtained via pre-positioned percutaneous sutures. Injection of the left femoral artery through contralateral access demonstrated a thrombosis extending on the entire length of the common femoral artery as well as the distal external iliac artery (Fig. 1A), with subocclusion of the vessel. Mechanical thrombectomy using Rotarex, (Fig. 1B) was performed through a 6 French cross-over sheath placed in the right femoral artery, allowing immediate antegrade blood flow restoration in the left common femoral artery (Fig. 1C) and absence of distal embolization (Fig. 1D).

Percutaneous mechanical support devices, inserted through large bore sheaths, are used increasingly in the catheterization laboratory for hemodynamic support. Vascular complications are rare, notwithstanding they may limit patient outcomes. Comprehensive assessment of femoral access upon retrieval of the devices/sheaths, commonly using a contralateral femoral access, allows for prompt recognition and treatment of vascular complications.

Conflict of interest: None declared

Address for correspondence: Sophie Degrauwe, MD, Department of Cardiology, Rue Gabrielle-Perret-Gentil 4, 1205 Geneva, Switzerland, tel: +41 7955320 94, fax: + 412237272 29, e-mail: sophie.degrauwe@hcuge.ch

Received: 1.09 .2020

Accepted: 14.10 .2020

Work was performed at Geneva University Hospital.

This article is available in open access under Creative Common Attribution-Non-Commercial-No Derivatives 4.0 International (CC BY-NC-ND 4.0) license, allowing to download articles and share them with others as long as they credit the authors and the publisher, but without permission to change them in any way or use them commercially. 


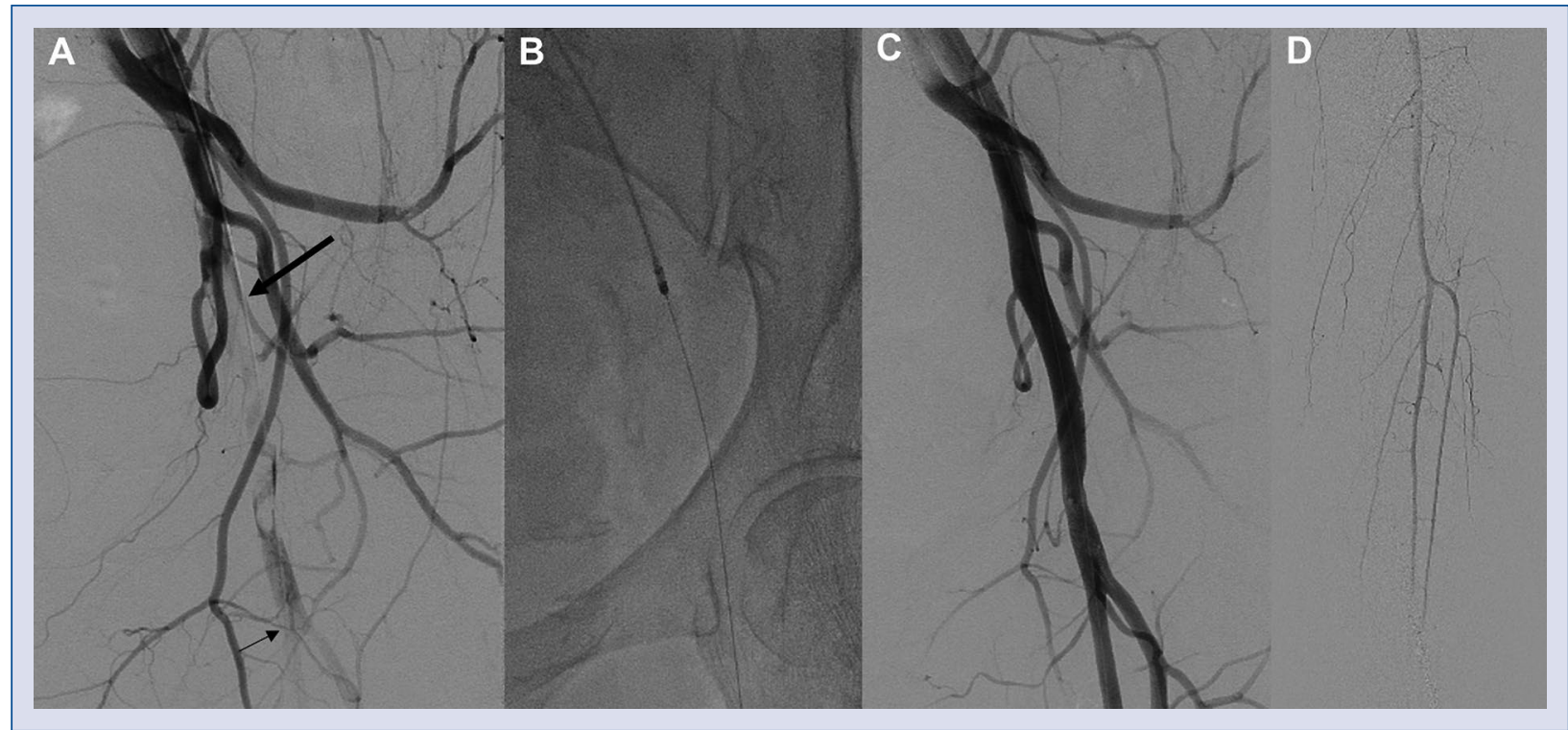

Figure 1. A. Subocclusive thrombosis extending on the entire length of the common femoral artery as well as the distal external iliac artery (large arrow). The small arrow denotes the faint opacification at the level of the femoral bifurcation; B. Mechanical thrombectomy using Rotarex, through a 6 French cross-over sheath placed in the right femoral artery; C. Restoration of antegrade blood flow in the left common femoral artery, absence of residual thrombosis; D. Below-the-knee angiography showing three patent vessels in the absence of distal embolization. 